\title{
POLÍTICAS COGNITIVAS E APRENDIZAGEM NO DESENVOLVIMENTO DE UM JOGO LOCATIVO
}

\author{
$*$ \\ Póti Quartiero Gavillon \\ Universidade Federal do Rio Grande do Sul - UFRGS - Brasil \\ Cleci Maraschin \\ Universidade Federal do Rio Grande do Sul - UFRGS-Brasil
}

\section{Resumo}

Este estudo discute o papel da teoria e da técnica na produção de um jogo locativo voltado para a aprendizagem. Esta discussão utiliza o conceito de política cognitiva para demonstrar o aspecto produtivo de realidade das teorias. O jogo locativo está sendo produzido pelo grupo de pesquisa Ecologias e Políticas Cognitivas, da Universidade Federal do Rio Grande do Sul, para o estudo do aprendizado relacionado a jogos. O presente trabalho avalia o processo de desenvolvimento do jogo até inciar-se o teste alfa. Neste processo observou-se que escolhas específicas na forma de criação no jogo produzem resultados congruentes com diferentes concepções de aprendizagem, o que possibilita maior poder de planejamento no design de jogos voltados ao aprendizado.

Palavras-chave: videogame, políticas cognitivas, aprendizagem.

\section{Introdução}

Os videogames têm assumido grande importância na cultura e nos modos de estabelecer relações de afinidade de um contingente de pessoas que inclui crianças, jovens e adultos (BAUM e MARASCHIN, 2011). Com isso, está emergindo uma nova área de pesquisa, que busca estudar os videogames e sua relação com a aprendizagem e com a sociedade. Por videogames entendo todas as simulações digitais, geradas por computador ou plataforma específica (como Xbox ou Playstation), onde um jogador é capaz de interagir com variáveis em busca de um objetivo determinado (GEE, 2005a; RANHEL, 2009). Descrevo os videogames como simulação no sentido em que Varela et al. (2003) descrevem a representação fraca: o jogo pode ser uma interpretação de algo que simula, e pode simular algo que não existe a não ser na imaginação do desenvolvedor. O jogo não é uma reprodução em escala 1:1 da realidade, nem necessita de verossimilhança (BAUM, 2012), ele é a criação de um mundo experiencial em si. Utiliza-se de elementos estéticos "para que o jogador consiga identificar os [outros] elementos que constituem o desafio/problema e a partir disso possa elaborar estratégias de solução" (BAUM, 2012). 
Gee (2007) destaca que jogar videogame, embora não seja a única, é uma alfabetização multimídia por excelência. Além de arregimentar símbolos, sons, gestos e gráficos para comunicar distintos significados, a prática do vídeogame condensa as ações de reconhecer (o equivalente da leitura) e produzir (o equivalente da escrita) atos com significação. Squire (2006), por sua vez, sugere compreendermos os jogos a partir do conceito de experiência projetada, entendendo que os mesmos são ambientes construídos que permitem diferentes modos de exploração e tipos de efeitos dependendo das ações do jogador. "Game designers 'escrevem' os parâmetros para a experiência dos jogadores, e a experiência do jogo como tal é mais bem descrita como uma interação entre o game designer e o jogador" (SQUIRE, 2006, p. 21). Os designers do jogo criam mundos imersivos com regras embutidas e relações entre objetos que permitem experiências dinâmicas. Essa organização serve, em termos gerais, para criar uma atmosfera que encoraje a performance do jogador, a competitividade ou a colaboração, de acordo com cada caso. As regras estabelecidas em determinado jogo definem as condições de possibilidade da experiência do jogador, sem determinar cada comportamento esperado. Os designers criam um campo de possíveis, mas em última instância, são os jogadores que decidem quais ações serão realizadas.

$\mathrm{Na}$ literatura atual sobre videogames existem controvérsias sobre quais seriam as possibilidades de aprendizado presentes nos jogos. Parece haver um consenso inicial de que os videogames ajudam a aprender, mas que tipo de aprendizagem e como isso acontece são bastante discutidos. Gee (2005b) aponta que muitos acreditam que o aprendizado é bem sucedido quando se memorizam fatos apresentados pelo jogo. Esta concepção guia a produção de muitos jogos, os quais costumam ser classificados como jogos sérios ou educativos. Tais jogos buscam apresentar um conteúdo externo ao jogo de forma divertida para que seja memorizado mais facilmente, processo ao qual nos referimos, neste trabalho, como instrução. Em oposição a essa proposta, há uma concepção mais ampla de aprendizado, sugerindo que os videogames possam ensinar de outras formas, abrangendo a experiência com sistemas complexos (que ajudaria em outros aprendizados) ou com elementos estéticos. Estas experiências teriam valor na educação no sentido de uma aprendizagem ampliada e não necessariamente ligadas à aprendizagem de conteúdos específicos (GEE, 2005a; GEE, 2005b; GEE, 2006; JENKINS, s/d).

Este trabalho discute estas possibilidades de aprendizado a partir do conceito de políticas cognitivas, que define as teorias sobre a cognição como produtoras e não somente explicativas. Sendo assim, é importante pensar como acontece esta produção de diferentes formas de aprendizado na criação de jogos. Para isto, será utilizado o processo de 
desenvolvimento de um jogo locativo voltado ao aprendizado.

\section{Políticas cognitivas}

Utilizamos e desenvolvemos o termo política cognitiva sugerido por Kastrup (1999 e 2005). Esta autora propõe um deslocamento do interesse no funcionamento e na estrutura da cognição para as práticas concretas que a configuram, sua discussão concentra-se nas práticas pedagógicas e de aprendizado. Ela sugere, nesse campo, duas políticas possíveis: uma recognitiva, centrada nos resultados e na solução de problemas, que busca assegurar uma obediência e um domínio do mundo. A segunda política possível seria uma política inventiva que promoveria a continuidade da cognição no campo da multiplicidade e do agenciamento, esta busca uma constante abertura da cognição para o novo e um movimento incessante de diferenciação, mantendo qualquer regra de funcionamento como temporária e passível de reinvenção.

A pedagogia e a aprendizagem não encerram, contudo, os campos de ação onde a cognição pode ser modulada, assumimos que a prática científica também implica uma política cognitiva, e recorremos a esta para destacar uma dimensão processual da cognição em que existe um primado das práticas que a engendram e dos processos que lhe dão forma, reconhecendo sua dimensão temporal e transformação permanente. O que se obtém em cada um desses regimes são fluxos híbridos (LATOUR, 1994) compostos por sujeitos, técnicas, objetos e instituições. Pesquisar a cognição se trata de acompanhar, através de suas práticas, o modo como uma inteligibilidade se constrói.

Recorremos à expressão política cognitiva como forma de destacar que conhecer envolve sempre uma posição em relação a si e ao mundo, um ethos. Implica em recusar um mundo dado do qual somos apenas capazes de fazer representações, mas apostar na ideia de um mundo que é efeito da prática cognitiva. É investir em uma política onde a invenção não é apenas um processo cognitivo entre outros, mas uma maneira de ser e de viver no mundo; o que coloca o problema da cognição teórica e existencialmente. Tal como sugere (Kastrup et al., 2008), "não se chega à cognição inventiva por adesão teórica, mas por práticas cognitivas efetivas" (p.13). Para definir as políticas cognitivas envolvidas, utilizaremos, em conjunto com os termos sugeridos por Kastrup (1999), a definição de representação forte e fraca de Varela et. al (2003), que equivalemos, respectivamente, à política recognitiva e à inventiva. A representação fraca (VARELA et al., 2003) tem relação com o uso mais cotidiano do termo, usado para definir qualquer coisa que possa ser interpretada como se referindo a outra, um 
exemplo de representação fraca é um mapa, o mapa se refere a uma determinada área e representa alguns de seus aspectos, assim interpretando esta área como sendo de certa forma. A representação fraca pode ser entendida como baseada na interpretação, pois quando algo se refere a outra coisa sempre envolve uma interpretação, e não há preocupação com a definição da origem do significado como na representação forte. Tal sentido de representação é fraco por não ter um comprometimento epistemológico ou ontológico fechado. Enquanto a representação fraca se propõe a explicar um aspecto da cognição, a representação forte generaliza e explica toda cognição a partir da representação. A política cognitiva inventiva realiza mais do que uma crítica à representação forte, , através da ideia de uma representação fraca, é um convite a pensar a possibilidade de outras práticas. Assim, colocamos em foco a aprendizagem em um sentido amplo, e não ligado estritamente à instrução e à resolução de problemas (Gavillon, 2014).

No caso dos jogos educativos onde o conteúdo seja colocado como um modelo de conhecimento, acreditamos haver uma relação entre essa proposta e a explicação representacionista da mente. A memorização de fatos, modelos, fórmulas ou algoritmos se mostra mais relevante se considerarmos que existe uma realidade objetiva externa a ser por eles representada. O representacionismo conduz a uma política de recognição, que toma a cognição na perspectiva da resolução de problemas. Se partimos de uma representação forte, onde os modelos de fato são tomados como equivalentes às coisas representadas, então a tarefa cognitiva seria reconhecer as coisas e resolver os problemas. A cognição é definida, assim, como aplicação de modelos ou algoritmos, que podem ser aprendidos como conteúdo. A representação forte não é necessariamente assumida em um jogo que busca apresentar conteúdo para memorização, mas a performance proposta nos dois casos é semelhante e pode ser explicada pelo reconhecimento de fatos e resolução de problemas relativos a um mundo objetivo.

A criação de novas formas de habitar o mundo presente na representação fraca pode ser relacionada com as experiências de aprendizado no sentido amplo, pois podemos perceber a dinâmica em que o jogador conhece um jogo criando formas de o habitar. O jogo é projetado com regras limitantes, mas possui possibilidades de ação incalculáveis, que somente existem de fato quando inventadas pelos jogadores. Neste aspecto, novamente, devemos atentar para que uma explicação não exige a outra, mas o modo como o aprendizado é performado a partir da proposta de representação fraca e de aprendizado amplo nos jogos é semelhante. Assim, o aprendizado acontece de forma imersiva, exploratória e inventiva. 


\section{Problema de Pesquisa}

Este trabalho busca observar como se produzem diferentes possibilidades de aprendizagem em um jogo locativo a partir de seu processo de criação. Estas diferentes possibilidades colocadas no jogo são avaliadas a partir do conceito de política cognitiva, atentando para as diferenças entre aprendizado baseado em uma representação forte, ou tomado em um sentido mais amplo.

\section{Método}

O jogo está sendo criado pelo grupo de pesquisa e extensão Ecologias e Políticas Cognitivas, da Universidade Federal do Rio Grande do Sul, em parceria com a Fundação Zoobotânica do Rio Grande do Sul como parte do projeto de pesquisa: “Oficinando em Rede: Experiências de Si em Espaços de Afinidade com Videogames" (Maraschin, 2011), utilizando a plataforma ARIS (realidade aumentada e narrativas interativas, em inglês, Augmented Reality and Interactive Storytelling), "uma ferramenta de código aberto para produção rápida de experiências educacionais locativas e interativas centradas na narrativa" (GAGNON 2010, p. 1). ARIS (http://arisgames.org/) é uma ferramenta de autoria e, ao mesmo tempo, um aplicativo, que possibilita a criação e reprodução de jogos, passeios e histórias interativas, utilizando-se de tecnologia GPS e QR Codes para proporcionar aos jogadores experiências em um mundo híbrido de personagens interativos virtuais, itens e meios de comunicação em um espaço físico.

A criação do jogo acontece presencialmente em reuniões semanais, e em interações assíncronas via correio eletrônico ou outras ferramentas digitais e atividades com o ARIS. Para criar o jogo, o grupo realiza seminários teóricos, estudo do ARIS, visitas ao local onde o jogo será localizado (o Jardim Botânico de Porto Alegre), criação de protótipos e testagens.

Foi criado, em agosto de 2012, um jogo simples para aproximação do grupo com a ferramenta de edição e com a tecnologia dos tablets. Posteriormente, foram utilizados diversos instrumentos para planejar o jogo, como mapas conceituais, fluxogramas, quadro branco e editores de texto. O grupo realiza estudos de conteúdo (sobre a história do Jardim Botânico, por exemplo) para dar suporte a seus roteiros, de forma realista ou como inspiração para alegorias. Quando novas inclusões no jogo fazem com que ele atinja um formato que o grupo acredite que deva ser avaliado, são realizados testes com os iPads no local físico do jogo, ou utilizando funções para simular o deslocamento. A análise se baseia na pesquisa- 
intervenção, e é feita através da participação no processo de desenvolvimento com registro em diários de campo.

Como estratégia de produção de conhecimento (NEVES, 2005) utilizo a cartografia, formulada por Deleuze e Guatarri (1995) e desenvolvida, entre outros, por Passos e Benevides (2009) e Kastrup (2009). Essa estratégia visa a acompanhar um processo, e não a representar um objeto. Deleuze e Guattari utilizam o termo cartografia para se referir ao uso dos mapas como forma explicativa:

O mapa é aberto, é conectável em todas as suas dimensões, desmontável, reversível, suscetível de receber modificações constantemente. Ele pode ser rasgado, revertido, adaptar-se a montagens de qualquer natureza, ser preparado por um indivíduo, um grupo, uma formação social. Pode-se desenhá-lo numa parede, concebê-lo como obra de arte, construí-lo como uma ação política ou como uma meditação. (DELEUZE e GUATTARI, 1995, p. 19)

Nas regras tradicionais do método científico, o sujeito-pesquisador e objetopesquisado ocupam lugares fixos, sendo termos preexistentes à ação do pesquisar. No que aqui proponho, o pesquisador se percebe como integrante da investigação, observador de seus próprios movimentos de conhecer (KASTRUP 2008) e procura afirmar-se através do encontro com o objeto e não no distanciamento dele. O critério de validação não está dado pela comprovação de uma realidade independente, mas por uma validação distribuída que inclui os participantes, os efeitos e os pares que compartilham do mesmo domínio de conhecimento (PASSOS e KASTRUP 2013). Pesquisar, assim, é tomado como um modo de produzir conhecimentos e, dessa forma, potencializar invenções e abrir outras possibilidades de existência: "o pesquisador não se posiciona como um intérprete, mas como agente de invenção de novas possibilidades, de rupturas de sentido" (TANIKADO, 2010, p. 21). Tal postura se aproxima da prática do cartógrafo assumida como ética, estética e política (ROLNIK, 1995):

Ética, porque o que a define não é um conjunto de regras tomadas como um valor em si para se chegar à verdade (um método), nem um sistema de verdades tomado com um valor universal: ambos são da alçada de uma posição de ordem moral. (...) Estética, porque não se trata de dominar um campo de saber já dado, mas sim de criar um campo no pensamento que seja a encarnação das diferenças que nos inquietam, fazendo do pensamento uma obra de arte. Política, porque se trata de uma luta contra as forças em nós que obstruem as nascentes do devir: forças reativas, forças reacionárias. (p. 246)

Não me parece adequado, portanto, supor um único modo de conhecer dito científico a ser buscado por todos, como proposto na representação forte. O modo como pesquisamos e, assim, o modo como conhecemos e escrevemos é marcado por nossas escolhas teóricas, 
políticas e afetivas. É, certamente, afetado por nossa história pessoal, por oportunidades e encontros tidos. Essa perspectiva metodológica se associa a postura de representação fraca, como discutirei adiante, e a uma política cognitiva inventiva.

Todo pesquisar produz uma intervenção, criação de sujeitos, objetos, conhecimentos, de territórios de vida. Nosso perguntar indaga sobre os modos de viver, existir, sentir, pensar, próprios de nossa cultura ou de outras. O próprio fato de perguntar produz, ao mesmo tempo, tanto no observador quanto no observado, novas possibilidades de viver. Nesse sentido, a pesquisa como uma intervenção, por sua ação crítica, amplia as condições de um trabalho compartilhado. Há mudanças de parâmetros de investigação no que tange a neutralidade e a objetividade do pesquisador, assim como a produção concomitante do sujeito e do objeto.

Sendo assim, uma proposta de objetividade é inadequada. Para a substituir, Maturana (2001, p. 147) propõe um comprometimento "em não deixar seus desejos ou preferências distorcerem ou interferirem em sua aplicação do critério de validação das explicações científicas", ou seja, uma busca por seguir os critérios estabelecidos pela comunidade científica. No caso deste trabalho, tal comprometimento se concretiza no uso do método cartográfico e de seus critérios de validação distribuída (PASSOS e KASTRUP, 2013).

Existe uma diferença quando se pergunta o porquê de um fenômeno ou quando se pergunta como opera esse fenômeno (Maraschin, 2004). Na primeira posição, o observador busca uma justificação, um fundamento ou princípio explicativo que dê conta do fenômeno, constituindo uma relação de causalidade linear.

\section{Análise}

Durante o processo de desenvolvimento do jogo o grupo oscilou entre priorizar a criação a partir da narrativa ou da jogabilidade. Inicialmente, houve a tentativa de partir de uma narrativa envolvente para tornar o jogo interessante, mas houve dificuldades em programar e se focou o desenvolvimento na jogabilidade. Na composição do jogo sempre esteve presente o aspecto tanto da narrativa quanto da jogabilidade, diferencia-se as duas posições para explicitar o movimento do grupo de tomar uma delas como eixo paradigmático que organiza o trabalho.

Percebemos que priorizar a narrativa acarretava maior atenção aos conteúdos. Conteúdos por vezes temáticos (sobre botânica ou outras áreas da biologia); históricos (sobre o Jardim Botânico); geológicos e geográficos (sobre o local onde se passa o jogo) ou de conhecimento popular (sobre lendas urbanas da região ou personagens famosos). 
O conteúdo temático apresentou-se, por exemplo, através da proposta recorrente de uso dos nomes científicos das espécies envolvidas, como curiosidade ou como parte de um desafio. Surgiu a ideia de criar atividades com perguntas sobre a flora do Jardim Botânico que conduzissem os jogadores a explorar o local ou fossem respondidas pelas informações contidas no jogo, na descrição de itens ou na fala de personagens. Os desafios consistiriam em conjuntos de perguntas a serem respondidos corretamente para que se ganhassem pontos extras, ou mesmo para possibilitar a continuidade do jogo.

O conteúdo histórico esteve presente em uma pesquisa sobre a história do Jardim Botânico. A partir da pesquisa o grupo se interessou por um de seus idealizadores. O grupo considerou utilizar o personagem através da inserção de fragmentos fictícios de seu diário, para revelar parte da trama e envolver o jogador.

$\mathrm{O}$ conhecimento geológico e geográfico referiu-se à busca por conhecer a representatividade das coleções da flora do Jardim Botânico em relação a região e por trazer informações em diferentes tempos geológicos.

O conhecimento popular consiste na ideia de usar uma lenda urbana de Porto Alegre, que trata de supostos assassinatos cometidos por um linguiceiro que viveu na Rua do Arvoredo.

Quando a criação do jogo estava centrada na narrativa, o grupo buscava utilizar diversas referências para suas criações e procurava inspiração nesses conteúdos, buscava-se apresentá-los ou os representar de forma correta ou educativa, em especial no que se refere à botânica. Se levantou a questão de por que não considerávamos criar uma história totalmente fantasiosa, que se passasse em um lugar imaginário, para depois ligá-lo ao local físico onde a história seria jogada. A resposta a esta questão envolvia o fato de buscarmos maior interação entre físico e digital e, por isso, seria melhor conceber histórias que se referissem ao próprio local. A discussão é pertinente e demonstra que o trabalho a partir da narrativa buscou a interação entre físico e digital através de conteúdos. Utilizamos aqui o termo conteúdo para dar importância ao caráter informativo e representacional que pareceu assumir. O trabalho baseado na narrativa envolveu uma busca por intencionalidade, ou seja, que os componentes do jogo se referissem a algo e por representações consideradas corretas. Os objetos representados por vezes eram subvertidos na narrativa, como no exemplo do personagem do padre Rambo, cujo diário teria conteúdo inventado pelos desenvolvedores, mas o grupo não considerou criar uma história totalmente nova para o surgimento do Jardim Botânico, sem baseá-la em fatos relevantes para o local. Buscou-se ancorar a narrativa em fatos históricos ou científicos. 
É claro que pode haver uma preocupação instrucional sem a necessidade de se deixar tomar por uma concepção forte de representação. Um exemplo disso seria adequar os conteúdos do jogo aos conteúdos das séries específicas da população escolar a que o jogo se destinaria, transformando-o em uma espécie de reforço escolar. Tal empreendimento focaria o conhecimento declarativo por acreditar que é esse o privilegiado pela escola, não por ser ontologicamente mais importante. O ensino na forma de transmissão de conteúdo pode ser explicado também através da representação fraca, a qual considera a existência das representações, do reconhecimento e da resolução de problemas. Aproximamos a forma de ensino instrucional à representação forte por fazer produzir uma performance centrada naquilo que esse modo explicativo considera mais importante: a criação de modelos formalizados a serem aplicados aos conteúdos concretos. Na representação forte, o conhecimento declarativo de um modelo abstrato é a forma mais precisa de conhecimento possível e, portanto, busca-se ensinar os modelos formais que podem ser aplicados na ação.

As formas que utilizamos para explicar a cognição implicam diferentes práticas de ensino, diferentes políticas que assinalam um lugar específico para as representações, modelos e criação. As práticas são sempre performadas em um meio político e se relacionam a outras concepções, ou seja, a política cognitiva não dita uma única forma de existência, mas participa da produção das experiências. O conceito de políticas cognitivas foi utilizado neste trabalho para aproximar as explicações teóricas sobre cognição da discussão sobre os modos de aprender privilegiado nos videogames (a qual, obviamente, se relaciona com a educação formal). Dessa forma, quando afirmamos que houve preocupação com a apresentação correta de conteúdos no design do jogo, apontamos que se atuou de uma forma ligada à posição da representação forte. A representação de conteúdo existe também na representação fraca, mas não com a mesma centralidade, e uma performance alinhada a essa política cognitiva atentaria mais às formas de interação que compõem a experiência do que à precisão da apresentação dos conteúdos (Gavillon, 2014).

Enquanto o desenvolvimento do jogo centrou-se na jogabilidade, houve menos propostas voltadas ao conteúdo, os esforços foram dirigidos, principalmente, para desenvolver uma jogabilidade capaz de estruturar a experiência de jogo da forma desejada. Os elementos narrativos, em vez de serem voltados a um conteúdo específico a ser representado, tiveram papel de suporte à jogabilidade escolhida. Quando decidimos criar armadilhas para os jogadores, concebemos personagens que não apareciam no mapa e eram ativados automaticamente por proximidade. Para um dos personagens escolhemos um lagarto, animal encontrado no Jardim Botânico. Para demonstrar a centralidade da jogabilidade e a pouca 
preocupação com uma representação fidedigna, utilizo a primeira fala desse personagem no jogo: “OH! Você caiu na minha cova!! Para sair deve deixar um item”. Quando a ideia foi proposta, surgiu uma dúvida sobre a correção do termo cova no contexto e foram feitas propostas para utilizar ninho, toca ou para descartar o personagem como armadilha. As dúvidas foram rapidamente deixadas de lado e o personagem mantido como estava, pois consideramos útil a jogabilidade proposta. Certamente o personagem estava referido ao Jardim Botânico, mas de uma maneira alinhada à representação fraca, ou seja, interpretando e produzindo algo com foco na pertinência para o contexto de aplicação (o jogo) e não em uma correspondência estrita com a linguagem correta (termo para designar o local onde vive um lagarto).

Quando foram criadas medalhas para feitos no jogo, discutimos quais títulos poderíamos utilizar. Surgiu a ideia de utilizar "botânico iniciante" e "mestre botânico" e, em oposição, uma ideia de que estes seriam termos enganosos, pois o jogador não se tornaria um botânico real. Nesse momento podemos perceber uma preocupação representacional forte e uma fraca claramente $\mathrm{O}$ grupo optou por utilizar os títulos citados concordando com a afirmação de um dos participantes "é claro que eles não vão virar botânicos, isso todo mundo sabe, mas isso é no jogo!". A afirmação demonstra a ideia de que o que acontece no jogo com o jogador não é isomórfico ao que acontece fora dele com o mesmo jogador. Nesse sentido, um jogador poderia enunciar para outro "eu sou um botânico experiente" e estar correto dentro do contexto dado pela relação com o jogo.

Danholt (2005) demonstra a agência dos objetos através de uma descrição do processo de design centrada no uso de protótipos. Uma versão inicial, reduzida, de demonstração ou de teste pode ser considerada protótipo, o qual, segundo o autor, é performativo, o que implica um foco no fazer. Essa definição de protótipo descreve o jogo "Um dia no Jardim Botânico", visto que é uma versão inicial de um jogo, sendo testada para dar continuidade ao desenvolvimento. Os protótipos, assim como outros agentes não-humanos, possibilitam a existência de novos entendimentos e ao mesmo tempo são performáticos produzindo novas relações a partir destes entendimentos. Um processo de design envolve vários tipos de materialidades, objetos e corpos interferindo e afetando uns aos outros (DANHOLT, 2005). O estudo relacionado a protótipos possui segundo o autor uma dupla dimensão, ele se refere tanto ao artefato quanto aos seus usuários, de forma que o design e a prototipagem são entendidos como processos mutualmente transformadores. $\mathrm{O}$ artefato e o usuário não são completamente separados, ou simplesmente interativos, mas se transformam de maneira significativa. Protótipo pode ser sinônimo de modelo, mas um protótipo performativo não 
trata de um modelo de representação forte, e sim de uma possibilidade de mudança progressiva em um caminho determinado, ou seja, um modelo encarnado. A criação de um protótipo cria uma representação que ao mesmo tempo possibilita maneiras específicas de ver aquilo que se pretende construir e resiste a outras. O caminho é determinado no sentido de excluir entendimentos alternativos e é trilhado progressivamente tomando como base o que se tinha antes, uma diferença no tempo, que não vai em direção a uma verdade, mas pode ser descrita de maneira incremental. Essa descrição do protótipo inclui uma modelização e uma representação, mas de forma fraca, de forma que o modelo resultante consiste em uma construção dentre muitas possíveis.

O jogo "Um dia no Jardim Botânico", se tomado como um protótipo como proposto por Danholt, afeta e é afetado pelos seus usuários. Utilizo esta proposta teórica para pensar a ação do protótipo em relação às políticas cognitivas envolvidas. O jogo ao mesmo tempo propõe interações baseadas em uma concepção de cognição e é modificado pelos jogadores, eventualmente questionando as proposições explicativas de seus desenvolvedores. Assim, percebemos que a teoria não é uma aproximação da verdade, mas um conjunto explicativo capaz de produzir formas de interação (performatividade do jogo) e de ser questionado a partir das interações resultantes. A pesquisa envolvendo protótipos, assim, é tanto sobre o protótipo quanto sobre seus usuários, pretende-se estudar a cognição dos jovens que utilizam o jogo, mas ao mesmo tempo deve-se atentar para as formas do jogo predispor o jogador à ação, produzindo a própria cognição que se busca estudar.

A dupla dimensão do estudo de protótipos evidencia tanto a agência dos não-humanos (o protótipo) quanto o caráter produtivo das explicações teóricas. Este caráter produtivo é importante para pensarmos as explicações em termos de políticas cognitivas, pois estas são explicações que são produzidas em uma rede de controvérsias e que atuam nestas, predispondo os atores a determinadas ações e não a outras. É por isso que o jogo foi capaz, em um teste, de produzir um tipo de interações específico (altamente relacionado com ambiente em que se inseria), e que essas interações levaram a repensar as explicações teóricas que o grupo utiliza para a produção do jogo.

Uma teoria sempre possui uma dimensão política, por ser temporal e produtiva, mas nem sempre uma teoria sobre a cognição (uma política cognitiva) se supõe tendo carater político. Se ela se diz forte, única, ou objetiva ela se postula na forma de certeza e não de política, como correta. Assim como uma determinada teoria pode se dizer objetiva, ela corresponde à uma atitude igual frente a outras teorias, considerando-as corretas ou incorretas. 
No momento em que sigo o caminho explicativo da objetividade sem parênteses e pretendo ter acesso privilegiado à realidade, que é o que validaria meu explicar e, portanto, meu agir, aquele que não está comigo, aquele que não aceita minha referência à realidade está equivocado e é, portanto, ipso facto negado. (MATURANA, 2001, p. 37)

O que fazemos é apontar que mesmo essas teorias que se julgam objetivas são políticas, demonstrar que a representação forte tem uma política implícita, pois ao se dizer apolitica produz um resultado específico. Este resultado, no caso da representação forte, é uma forma de ensino (e desenvolvimento de jogos educativos) centrada na transmissão de conhecimento através de modelos abstratos, na instrução, e no conhecimento declarativo. Essa política cognitiva, embora não represente a escolha teórica declarada do grupo de pesquisa, esteve presente nas controvérsias na criação do jogo. Em especial, uma posição alinhada com a representação forte foi presumida pelo grupo no contexto escolar (através da idéia de conteúdo específico a ser ensinado), e o grupo teve dificuldade em imaginar os usos possíveis de um jogo baseado nas ideias da representação fraca nesse mesmo contexto. A política de buscar representações corretas do mundo se inclui aqui, contrapondo a idéia de uma representação (fraca) que pode ser uma interpretação diferente, ou até mesmo a produção daquilo que representa (Gavillon, 2014). Também foi possível perceber que a concepção de ensino como transmissão de conteúdo surgiu diversas vezes nos questionamentos que alguns membros do grupo faziam sobre a possibilidade de aprendizado no jogo, pensando se o aprendizado operativo ("como") poderia ser considerado da mesma forma que o aprendizado declarativo (“o quê”). A representação fraca admite a existência desses dois tipos de conhecimento, mas é a representação forte que eleva o saber o quê a um nível hierárquico mais alto.

As formas explicativas da representação forte definem modos de produzir experiências de aprendizagem. Assim, se penso que existe uma posição privilegiada a partir da qual posso ter acesso direto à realidade, a aprendizagem consiste em levar o sujeito a essa posição munido dos modelos adequados. A teoria produz aquilo que descreve e essa é uma dimensão politica. Assim, não se trata de negar a possibilidade de explicar a cognição a partir da representação forte, mas de pensar a representação como um dos caminhos explicativos possíveis, o qual é associado a performances específicas.

A característica de negociação política leva a perguntar sobre como podemos construir coletivamente as relações com o aprender que desejamos, a partir de determinada política cognitiva como proposta articuladora. Essa pergunta é base de propostas para a continuidade da pesquisa, estudando o uso de jogos em ambiente escolar para pensar as possibilidades de 
produção de aprendizado em um ambiente de ensino formal.

Pensado a partir do conceito de política cognitiva, o contexto da pesquisa não é somente um cenário que dá colorido especial à teoria, que por sua vez seria universal. Ao invés disso, a teoria é considerada como uma referência para a prática, aplicada em um contexto que ao mesmo tempo é modificado e modifica a teoria localmente.

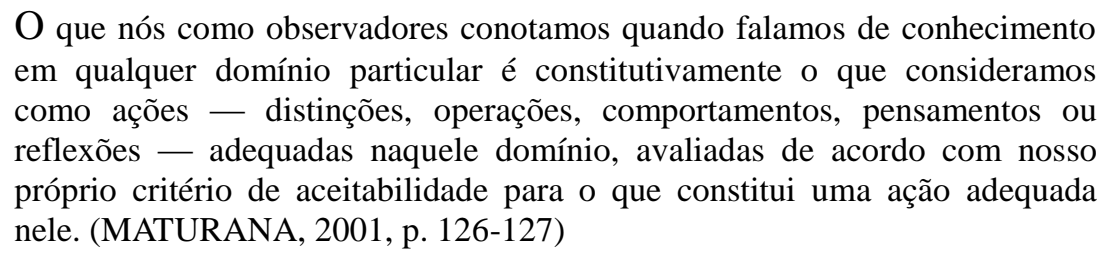

Assim, pode-se pensar a criação de forma específica e, com isso, repensar a teoria, a qual continua podendo ser utilizada como referência para práticas em outros espaços. As teorias, entendidas como políticas cognitivas são modos de estar no mundo, de estabelecer relações, mas estes modos podem ser atuados de diferentes formas em diferentes contextos.

A performatividade dos artefatos produzidos pelos designers implica, neste estudo, duas coisas. Primeiro, os jogos desenvolvidos de uma determinada forma ou a partir de uma determinada teoria possibilitam e produzem relações específicas e, segundo, as ferramentas utilizadas para a produção têm esta mesma agência. Assim, a performatividade no design aponta para a agência da própria teoria utilizada no design, demonstrando seu caráter produtivo e, consequentemente, político. Essa relação produtiva da teoria com os objetos que estuda e desenvolve é o que caracteriza a política cognitiva.

\section{Conclusão}

As controvérsias sobre aprendizagem (nos jogos e na cognição) se ligaram às controvérsias sobre narrativa e jogabilidade, em nosso trabalho. Nos momentos em que nos posicionamos de forma a dar centralidade para a jogabilidade nossas ações no desenvolvimento se alinharam com a representação fraca (e o aprendizado no sentido amplo) na controvérsia sobre aprendizagem. Da mesma forma, a centralidade da narrativa nos levou a uma performance que entendemos como próxima à proposta pela representação forte (e pelo aprendizado no sentido mais instrucional). O grupo não mudou seu entendimento sobre a controvérsia referente ao aprendizado, mas nossas ações mudaram, concomitantemente com a mudança de posição em relação ao que deveria fundamentar o design. Ou seja, mesmo que, teoricamente, uma posição não implique a outra necessariamente, na prática, isto ocorreu. 
Assim, afirmamos que programar um jogo com a jogabilidade como eixo paradigmático implicou um jogo mais adequado às propostas de aprendizagem em um sentido amplo, e quando a narrativa foi colocada em posição de centralidade o jogo resultante tornou-se mais relacionado ao ensino como transmissão de conhecimentos representacionais. Acompanhar esses processos e suas linhas de força revela-se importante para pensar estratégias de design eficientes para o tipo de ensino proposto e reforça o caráter performático de uma aprendizagem não centrada prioritariamente na representação. Essa performance se daria na ação, na jogabilidade, devendo incluir o aspecto pragmatico e não somente o declarativo da linguagem.

Apesar da escolha teórica realizada pelo grupo de pesquisa, as controvérsias seguiram emergindo nas práticas, pois as ações são sempre negociadas politicamente em uma rede de produção repleta de atores. Este trabalho aponta para a possibilidade (e pertinência) de pensarmos em como podemos produzir estratégias específicas de design com performances alinhadas com a política cognitiva inventiva. As controvérsias aqui evidenciadas podem ajudar desenvolvedores a planejarem sua forma de trabalho com atenção para seu posicionamento em relação às mesmas. A ligação entre as controvérsias sobre aprendizagem e jogabilidade/narrativa, aponta para o potencial inventivo de um design centrado na jogabilidade.

A partir dos resultados dessa pesquisa se torna possível evidenciar a potência da análise das forças que se interpõem em um trabalho em andamento. Essa é uma demonstração de que as políticas cognitivas não são teorias diretamente aplicadas, no sentido de modelos, mas sim referências, pistas que fazem parte de uma rede complexa de negociações que definem as ações em curso. Se, por um lado, programar um jogo a partir de determinada concepção gera experiências específicas, por outro, utilizar a concepção no jogo não garante que ela será efetivada em todo o processo de desenvolvimento. Compreender as forças que modulam as ações nos auxilia a buscar uma congruência operacional entre como se pensa (saber sobre) e como se faz (saber-fazer). Este exercício de auto-análise não é simples, pois exige um direcionamento da atenção para si.

Para produzir o tipo de cognição que desejamos, a partir de uma política cognitiva não basta apenas a atenção para as controvérsias em que nosso objeto de estudo ou desenvolvimento se insere, mas devemos pensar também sobre os processos de trabalho e estratégias de design. A questão que se impõe nesse ponto é como desenvolver jogos a partir de uma política cognitiva inventiva como estratégia de design? Essa pergunta, porém, não pode ser respondida apenas teoricamente e apresenta-se como um desafio processual no 
desenvolvimento de jogos educativos. As respostas encontradas em cada projeto não suprimem a pergunta, que subsiste nelas, como forma de organização.

\title{
COGNITIVE POLITICS AND LEARNING IN THE DEVELOPMENT OF A LOCATION BASED GAME
}

\begin{abstract}
This study discusses the role of theory and technique in the production of a location based game geared toward learning. This discussion uses the concept of cognitive politics to demonstrate the reality production aspect of theories. The locative game is being produced by the research group Ecologias e Políticas Cognitivas, of Universidade Federal do Rio Grande do Sul, to study learning related to games. This paper evaluates the development of the game until the alpha testing. In this process it was observed that specific choices in the way of creating the game produce results congruent with different conceptions of learning, which enables greater planning power in the design of games geared to learning.
\end{abstract}

Keywords: videogame, cognitive politics, learning.

\section{POLÍTICAS COGNITIVAS Y APRENDIZAJE EN EL DESARROLLO DE UN JUEGO LOCATIVO}

\section{Resumen}

Este estudio analiza el papel de la teoría y la técnica en la producción de un juego locativo orientado hacia el aprendizaje. Esta exposición se basa en el concepto de políticas cognitivas para demostrar el aspecto productivo de realidad de las teorías. El juego locativo está siendo producido por el grupo de investigación Ecologias e Políticas Cognitivas, de Universidade Federal do Rio Grande do Sul, para el estudio del aprendizaje relacionado con juegos. En este trabajo se evalúa el desarrollo del juego hasta inciar la prueba alfa. En este proceso se observó que las opciones específicas en la creación del juego producen resultados congruentes con diferentes concepciones de aprendizaje, lo que permite una mayor planificación en el diseño de juegos orientados al aprendizaje.

Descripción: juego, política cognitiva, aprendizaje.

\section{Referências}

Baum, Carlos. Sobre o videogame e cognição inventiva. Dissertação de mestrado. Programa de Pós-Graduação em Psicologia Social e Institucional, Universidade Federal do Rio Grande do Sul. Porto Alegre, 2012.

Baum, Carlos, Maraschin, Cleci. Explorando 'Arkham Asylum': sobre vídeo game e aprendizagem inventiva. Em Polis e Psique, Vol. 1, n2, p. 38-52, 2011. 
Deleuze, Gilles. Guattari, Félix. Mil Platôs - Capitalismo e Esquizofrenia. Vol. 2. Rio de Janeiro: Ed. 34, 1995.

Gagnon, David. J. ARIS: An open source platform for developing mobile learning experiences. Disponível em: http://arisgames.org/wp-content/uploads/2011/04/ARIS-GagnonMS-Project.pdf, 2010.

Gavillon, Póti Q. Videogames e Políticas Cognitivas. Dissertação de mestrado. Programa de Pós-Graduação em Psicologia Social e Institucional, Universidade Federal do Rio Grande do Sul, 2014.

Gee, James P. Why are videogames good for learning?. Disponível em: http://www.academiccolab.org/resources/documents/MacArthur.pdf, 2005a.

Gee, James P. What games have to teach us: an interview with James Paul Gee. Game Developer; Nov 2005; ProQuest pg. 9, 2005 b.

Gee, James P. Good videogames + good learning. Collected essays on videogames, learning and literacy. New York: Peter Lang Publishing, 2007.

Jenkins, Henry. Games, the new lively art. Disponível em: https://wiki.brown.edu/confluence/ download/attachments/7143524/jenkins.games.pdf, (s/d).

Kastrup, Virginia. A invenção de si e do mundo : uma introdução do tempo e do coletivo no estudo da cognição. Campinas, São Paulo: Papirus Editora, 1999.

Kastrup, Virginia. Políticas cognitivas na formação do professor e o problema do devirmestre. Em: Revista Educação e Sociedade, v.26, n.93, p. 1273-1288, set./dez, 2005.

Kastrup, Virginia. O método da cartografia e os quatro níveis da pesquisa-intervenção. Em: Castro, L. R. de; Besset, V. L. (Orgs.). Pesquisa-intervenção na infância e juventude. Rio de Janeiro: Trarepa/FAPERJ, 2008.

Kastrup, Virginia. O funcionamento da atenção no trabalho do cartógrafo. Em: Pistas do método da cartografia: pesquisa-intervenção e produção de subjetividade. Porto Alegre: Sulina, 2009.

Maraschin, Cleci. Pesquisar e intervir. Em Psicol. Soc. Porto Alegre, v. 16, n. 1. Disponível em <http://www.scielo.br/scielo.php?script=sci_arttext\&pid=S0102-

$71822004000100008 \& \operatorname{lng}=$ pt\&nrm=iso>, 2004.

Maraschin, Cleci. Oficinando em rede: experiências de si em espaços de afinidade com videogames. Ufrgs, Porto Alegre, 2011.

Maturana, Humberto. Cognição, ciência e vida cotidiana. Belo Horizonte: Ed. da UFMG, 2001 .

Neves, Rosane A. A invenção da psicologia social. Petrópolis: Vozes, 2005. 
Passos, Eduardo; Benevides, Regina. A cartografia como método de pesquisa-intervenção. Em: Pistas do método da cartografia: pesquisa-intervenção e produção de subjetividade. Porto Alegre: Sulina, 2009.

Passos, Eduardo; Kastrup, Virginia. Sobre a validação da pesquisa cartográfica: acesso à experiência, consistência e produção de efeitos. Fractal, Rev. Psicol., v. 25 - n. 2, p. 391-414, Maio/Ago, 2013.

Ranhel, João. O conceito de jogo e os jogos computacionais. In: Santaella, L. e Feitoza, M. (Eds.). Mapa do Jogo - A diversidade cultural dos games. Cengage Learning, Sao Paulo, 2009.

Rolnik, Suely. Entrevista a Lira Neto e Silvio Gadelha. Em: O Povo, Caderno Sábado: 06. 18/11/95, Fortaleza, 1995.

Squire, Kurt D. From content to context: Videogames as designed experiences. Educational Researcher, vol. 35, n. 8, p. 19-29, 2006.

Tanikado, Grace V. F. Virtualizando coletivos: tecnologias e pesquisa-intervenção. Dissertação de mestrado. Programa de Pós-Graduação em Psicologia Social e Institucional, Universidade Federal do Rio Grande do Sul. Porto Alegre, 2010.

Varela, Francisco J.; Thompson, Evan; Rosch, Eleanor. A mente incorporada: ciências cognitivas e experiência humana. Porto Alegre: Artmed, 2003.

Data de recebimento: $26 / 08 / 14$

Data de aceite: 23/03/2017

\section{Sobre os autores:}

Póti Quartiero Gavillon possui graduação em Psicologia pela Universidade Federal do Rio Grande do Sul (2010) e mestrado em Psicologia Social e Institucional pela Universidade Federal do Rio Grande do Sul (2013). Endereço Eletrônico: poti.gav@ gmail.com

Cleci Maraschin possui graduação em Psicologia pela Universidade Federal do Rio Grande do Sul (1982), Graduação em Licenciatura em Psicologia pela Universidade Federal do Rio Grande do Sul (1992), Mestrado em Educação pela Universidade Federal do Rio Grande do Sul (1987), Doutorado em Educação pela Universidade Federal do Rio Grande do Sul (1995) e Pós Doutorado pela Universidade de Wisconsin-Madison (2011). Endereço Eletrônico: cleci.maraschin@gmail.com 